\title{
Analisis Peramalan Stok Barang dengan Metode Weight Moving Average dan Double Exponential Smoothing pada Jovita Ms Glow Lamongan
}

\author{
Azza Wirdhatul Zannah, Teknik Informatika Universitas Islam Lamongan, Nur Nafi'iyah, Teknik \\ Informatika Universitas Islam Lamongan
}

\begin{abstract}
Abstrak - Jovita MS Glow Lamongan merupakan agen yang menjual produk kecantikan dari brand MS Glow, produk yang dijual di antaranya perawatan wajah, tubuh, kosmetik dengan perkembangan penjualan dari bulan ke bulan semakin meningkat maka dibutuhkan perhitungan perkiraan jumlah barang yang akan dibeli untuk meramalkan persediaan barang bulan berikutnya. Persediaan barang yang tidak tepat dapat menimbulkan kerugian maka perlu adanya sistem peramalan. Oleh karena itu penelitian menggunakan metode Weight Moving Average dan Double Exponential Smoothing untuk menentukan nilai error yang lebih kecil. Data yang digunakan pada penelitian ini mulai bulan Januari 2015 sampai bulan Desember 2016. Metode Weight Moving Average yaitu metode yang memberikan bobot yang berbeda untuk setiap historis sedangkan Metode Double Exponential Smoothing merupakan metode yang memiliki nilai pemulusan dua kali pada waktu sebelum data sebenarnya. Hasil peramalan kedua metode ini menghasilkan nilai error Weight Moving Average yaitu 698.7180 dan Double Exponential Smoothing yaitu 1.429.1015, sehingga Weight Moving Average adalah metode yang tepat digunakan untuk meramalkan persediaan barang karena memiliki nilai error yang lebih kecil.
\end{abstract}

Kata Kunci- Peramalan, Stok Barang, Weight Moving Average, Double Exponential Smoothing.

\section{Pendahuluan}

$\mathrm{J}$ ovita MS Glow Lamongan merupakan agen yang menjual produk kecantikan. Dengan perkembangan penjualan dari bulan ke bulan yang semakin bertambah, maka kami ingin mengetahui berapa jumlah barang yang akan terjual bulan berikutnya dengan mengacu pada penjualan bulan sebelumnya. Serta untuk mengetahui berapa jumlah barang yang harus disediakan untuk periode penjualan berikutnya.

Perhitungan persediaan barang sebelumnya di hitung secara manual, dengan cara menghitung berapa jumlah barang yang tersisa, cara tersebut tidak efisien karena pemilik hanya mengira jumlah barang yang akan dibeli dan sering terjadi kesalahan dalam perhitungan peramalan sehingga tidak sesuai dengan kebutuhan konsumen.

Azza Wirdhatul Zannah, Mahasiswa Teknik Informatika Universitas Islam Lamongan, email: azzawirdha83@gmail.com.

Nur Nafi' iyah, Dosen Teknik Informatika Universitas Islam Lamongan, email: mynaff26@gmail.com.
Dari permasalahan di atas timbul gagasan untuk membuat sistem peramalan dengan metode weight moving average dan double exponential smoothing. Tujuan penelitian ini adalah untuk mengetahui metode yang tepat dalam menghitung peramalan stok barang dengan tingkat nilai error yang lebih kecil.

Peramalan (Forecasting) adalah suata usaha untuk meramalkan keadaan dimasa mendatang melalui pengujian keadaan masa lalu peramalan bertujuan mendapatkan hasil yang mampu meminimumkan kesalahan dalam peramalan (forecast error).

Metode weight moving average adalah metode rata-rata bergerak yang banyak digunakan untuk menentukan trend dari suatu deret waktu. Metode ini digunakan untuk data yang perubahannya tidak cepat. Metode double exponential smoothing adalah metode penghalusan exponential adalah teknik peramalan rata-rata bergerak dengan pembobotandimana data diberi bobot oleh sebuah fungsi exponential. Penghalusan exponential merupakan metode peramalan rata-rata bergerak dengan pembobotan canggih, namun masih mudah digunakan.

\section{METODOLOGI PENELITIAN}

Dalam pembuatan sistem peramalan persediaan barang menggunakan metode weight moving average dan double exponential smoothing bisa diartikan sebagai metode yang berfungsi untuk mencari nilai error terkecil meramalkan jumlah persediaan barang yang nantinya hasil outputnya berupa perbandingan dua metode dengan jumlah nilai error terkecil. Persamaan 1 perhitungan menggunakan metode weight moving average:

WMA $=\frac{[\text { [D(Dt } * \text { bobot })}{\text { (Dbobot) }}$

WMA $=((30 \times 3)+(30 \times 2)+(20 \times 1)) / 3+2+1$

$=90+60+20 / 6=28.33333333$

$\mathrm{ERROR}=30-28.33333333=1.666666667$

Tabel 1 adalah data perhitungan metode weight moving average.

TABEL I DATA PERHITUNGAN WMA

\begin{tabular}{|l|l|r|l|l|}
\hline Bulan & $\begin{array}{l}\text { Tahu } \\
\text { n }\end{array}$ & Nilai & $\begin{array}{l}\text { Hitung } \\
\text { WMA }\end{array}$ & ERROR \\
\hline Januari & 2015 & 20 & 0 & \\
\hline Februari & 2015 & 30 & 0 & \\
\hline
\end{tabular}




\begin{tabular}{|l|r|r|r|r|}
\hline Bulan & Tahun & Nilai & Hitung & \multicolumn{1}{l|}{ WMA } \\
\hline Maret & 2015 & 30 & 28.333333 & 1.6666667 \\
\hline April & 2015 & 40 & 35 & 5 \\
\hline Mei & 2015 & 50 & 43.333333 & 6.66666667 \\
\hline Juni & 2015 & 50 & 48.333333 & 1.66666667 \\
\hline Juli & 2015 & 30 & 40 & 10 \\
\hline Agustus & 2015 & 20 & 28.333333 & 8.33333333 \\
\hline September & 2015 & 25 & 24.166667 & 0.83333333 \\
\hline Oktober & 2015 & 40 & 31.666667 & 8.33333333 \\
\hline November & 2015 & 35 & 35 & 0 \\
\hline Desember & 2015 & 40 & 38.333333 & 1.666666667 \\
\hline Januari & 2016 & 53 & 45.666667 & 7.333333333 \\
\hline Februari & 2016 & 66 & 57.333333 & 8.666666667 \\
\hline Maret & 2016 & 60 & 60.833333 & 0.833333333 \\
\hline April & 2016 & 65 & 63.5 & \\
\hline Mei & 2016 & 70 & 66.666667 & 1.533333333 \\
\hline Juni & 2016 & 55 & 61.666667 & 6.666666667 \\
\hline Juli & 2016 & 75 & 67.5 & 7.5 \\
\hline Agustus & 2016 & 60 & 64.166666 & 7 \\
\hline September & 2016 & 68 & 66.5 & 4.16666667 \\
\hline Oktober & 2016 & 80 & 72.666667 & 7.333333333 \\
\hline November & 2016 & 90 & 83 & 7 \\
\hline Desember & 2016 & 85 & 85.833333 & 0.833333333 \\
\hline & & & & \\
\hline
\end{tabular}

Persamaan 2 perhitungan menggunakan metode double exponential smoothing:

1. Menghitung nilai Ft

$F_{t}=\frac{\text { bulan geharang }+ \text { bulan laiu }}{2}$

2. Menghitung prediksi single exponential smoothing

$F_{\mathrm{t}+1}=F_{\mathrm{t}}+\alpha\left(Y_{\mathrm{t}}-F_{\mathrm{t}}\right)$

3. Menghitung prediksi double exponential smoothing

$F_{t+1}^{v}=F_{t+1}+\alpha\left(Y_{t}-F_{t+1}\right)$

Single Exponential $=(0.4 *(40-35))+35=37$

Double Exponential $=(0.4 *(40-37))+37=38.2$

ERROR $=38.2-50=11.8$

Tabel 2 adalah data perhitungan metode double exponential smoothing.

Pada kamus data ini terdapat lima tabel yaitu admin, persediaan barang, peramalan metode weight moving average, peramalan metode double exponential smoothing dan hasil akurasi. Dalam perancangan sistem ini database penyimpanan data adalah sebagai berikut:

Tabel persediaan barang berfungsi sebagai tempat menyimpan data persediaan barang seperti no, nama, nilai, bulan dan tahun, dengan no sebagai primary key. Proses tersebut dapat dijelaskan pada Tabel 3.

Tabel metode weight moving average berfungsi sebagai perhitungan peramalan persediaan barang seperti no, nama, bulan, tahun, nilai, has_prediksi, eror, dengan no sebagai primary key. Proses tersebut dapat dijelaskan pada Tabel 4.

TABEL II

DATA PERHITUNGAN DES

\begin{tabular}{|l|r|r|r|r|r|r|}
\hline Bulan & Tahun & Nilai & \multicolumn{1}{l|}{ PP } & \multicolumn{1}{l}{ SE } & \multicolumn{1}{l|}{ DES } & Error \\
\hline Januari & 2015 & 20 & 10 & 14 & 16.4 & 13.6 \\
\hline Februari & 2015 & 30 & 25 & 27 & 28.2 & 1.8 \\
\hline Maret & 2015 & 30 & 30 & 30 & 30 & 10 \\
\hline April & 2015 & 40 & 35 & 37 & 38.2 & 11.8 \\
\hline Mei & 2015 & 50 & 45 & 47 & 48.2 & 1.8 \\
\hline Juni & 2015 & 50 & 50 & 50 & 50 & 20 \\
\hline Juli & 2015 & 30 & 40 & 44 & 49.6 & 29.6 \\
\hline Agustus & 2015 & 20 & 25 & 27 & 29.8 & 4.8 \\
\hline September & 2015 & 25 & 22.5 & 23.5 & 24.1 & 15.9 \\
\hline Oktober & 2015 & 40 & 32.5 & 35.5 & 37.3 & 2.3 \\
\hline November & 2015 & 35 & 37.5 & 38.5 & 39.9 & 0.1 \\
\hline Desember & 2015 & 40 & 37.5 & 38.5 & 39.1 & 13.9 \\
\hline Januari & 2016 & 53 & 46.5 & 49.1 & 50.66 & 15.34 \\
\hline Februari & 2016 & 66 & 59.5 & 62.1 & 63.66 & 3.66 \\
\hline Maret & 2016 & 60 & 63 & 64.2 & 65.88 & 0.88 \\
\hline April & 2016 & 65 & 62.5 & 63.5 & 64.1 & 5.9 \\
\hline Mei & 2016 & 70 & 67.5 & 68.5 & 69.1 & 14.1 \\
\hline Juni & 2016 & 55 & 62.5 & 65.5 & 69.7 & 5.3 \\
\hline Juli & 2016 & 75 & 65 & 69 & 71.4 & 11.4 \\
\hline Agustus & 2016 & 60 & 67.5 & 70.5 & 74.7 & 6.7 \\
\hline September & 2016 & 68 & 64 & 65.6 & 66.56 & 13.44 \\
\hline Oktober & 2016 & 80 & 74 & 76.4 & 77.84 & 12.16 \\
\hline November & 2016 & 90 & 85 & 87 & 88.2 & 3.2 \\
\hline Desember & 2016 & 85 & 87.5 & 88.5 & 89.9 & \\
\hline & & & & & & \\
\hline
\end{tabular}

TABEL III

TABEL DATA PERSEDIAAN BARANG

\begin{tabular}{|l|l|c|c|c|}
\hline No & $\begin{array}{l}\text { Nama } \\
\text { Field }\end{array}$ & Tipe Data & Size & Keterangan \\
\hline 1 & No & Integer & 11 & Primary key \\
\hline 2 & Nama & Varchar & 30 & \\
\hline 3 & Bulan & Varchar & 15 & \\
\hline 4 & Tahun & Integer & 4 & \\
\hline 5 & Nilai & Integer & 11 & \\
\hline
\end{tabular}

TABEL IV

TABEL PERAMALAN METODE WEIGHT MOVING AVERAGE

\begin{tabular}{|c|l|c|c|c|}
\hline No & Nama Field & Tipe Data & Size & Keterangan \\
\hline 1 & No & Integer & 11 & $\begin{array}{c}\text { Primary } \\
\text { key }\end{array}$ \\
\hline 2 & Nama & Varchar & 30 & \\
\hline 3 & Bulan & Varchar & 15 & \\
\hline 4 & Tahun & Integer & 4 & \\
\hline 5 & nilai & Integer & 11 & \\
\hline 6 & Has_prediksi & Float & & \\
\hline 7 & Eror & Float & & \\
\hline
\end{tabular}

Tabel metode double exponential smoothingberfungsi sebagai perhitungan peramalan persediaan barang sepertino, 
nama, bulan, tahun, nilai, has_prediksi dan eror dengan no sebagai primary key. Proses tersebut dapat dijelaskan pada Tabel 5.

TABEL V

TABEL METODE DOUBLE EXPONENTIAL SMOOTHING

\begin{tabular}{|c|l|c|c|c|}
\hline No & Nama Field & $\begin{array}{c}\text { Tipe } \\
\text { Data }\end{array}$ & Size & Keterangan \\
\hline 1 & No & Integer & 11 & $\begin{array}{c}\text { Primary } \\
\text { key }\end{array}$ \\
\hline 2 & Nama & Varchar & 30 & \\
\hline 3 & Bulan & Varchar & 15 & \\
\hline 4 & Tahun & Integer & 4 & \\
\hline 5 & Nilai & Integer & 11 & \\
\hline 6 & Has_prediksi & Float & & \\
\hline 7 & Eror & Float & & \\
\hline
\end{tabular}

DFD level 0 ini adalah perhitungan persediaan barang, admin melakukan login kemudian mengisi dataset, setelah dataset terisi maka admin melakukan proses prediksi persediaan barang, Kemudian proses tersebut berupa hasil prediksi.Proses tersebut di jelaskan pada Gambar 1.

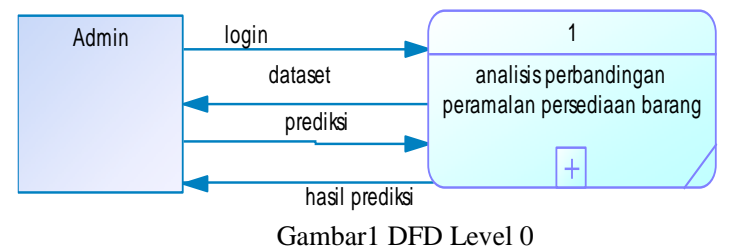

Pada DFD level 1 admin melakukan input dataset dan dimasukkan pada tabel dataset kemudian di masukkan pada tabel akurasi. Setelah itu admin melakukan perhitungan metode WMA kemudian dimasukkan pada tabel hasil peramalan WMA, admin melakukan peramalan metode DES dan dimasukkan pada tabel hasil metode DES. Kemudian admin melakukan akurasi data. Proses tersedut dapat di jelaskan pada Gambar 2.

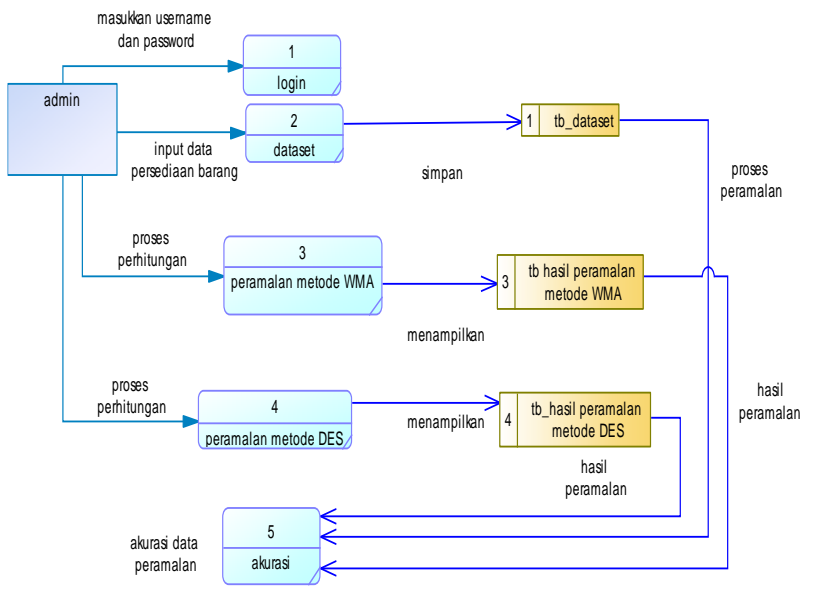

Gambar 2 DFD Level 1

Model konsep data atau Conceptual Data Modeling sebuah model diagram yang digunakan untuk menggambarkan basis data sebuah system. Pada CDM ini proses yang dilakukan adalah perhitungan persediaan barang dengan menggunakan prediksi metode WMA dan metode DES. Proses tersebut di jelaskan pada Gambar 3.

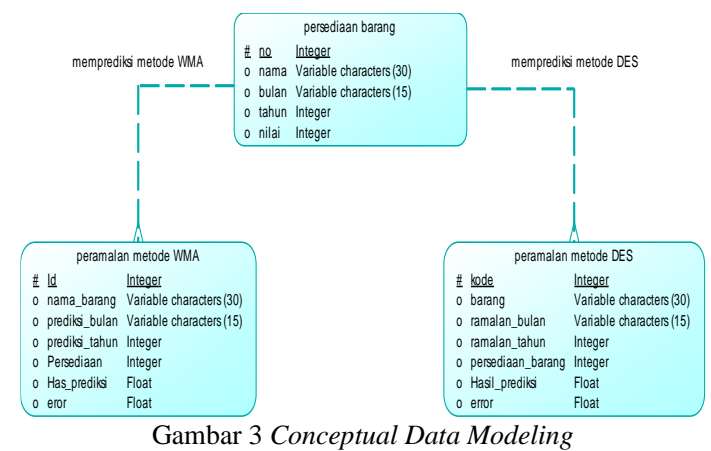

Pemodelan data fisik adalah generate dari konsep pemodelan data yang telah dibuat sebelumnya pada gambar 3. Pada PDM ini proses yang dilakukan adalah perhitungan persediaan barang dengan menggunakan prediksi metode WMA dan metode DES proses tersebut di jelaskan pada Gambar 4.

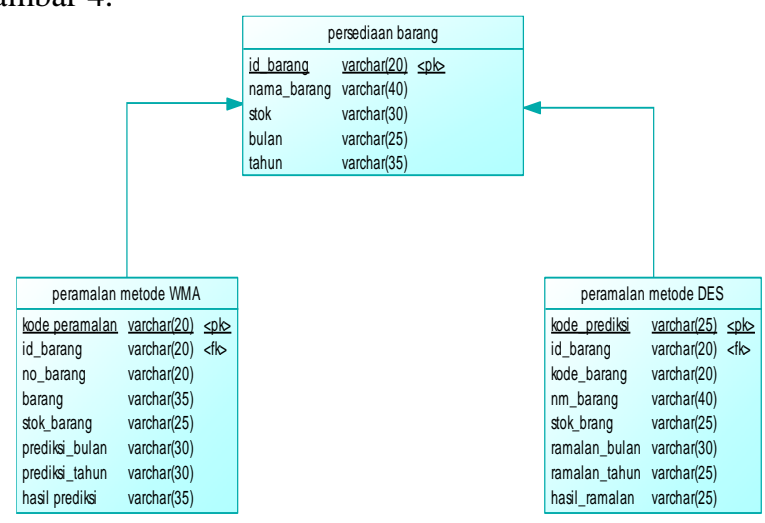

Gambar 4 Physical Data Modeling

\section{HASIL DAN PEMBAHASAN}

Pembahasan fitur merupakan kajian yang dilakukan untuk memberikan gambaran utama aplikasi. Adapun komponenkomponen utama yang ada pada aplikasi sebagai berikut:

Pada menu utama terdapat form data admin, form data persediaan barang, form peramalan metode weight moving average, form peramalan metode double exponential smoothing dan form hasil akurasi.

Pada form data persediaan barang memiliki tiga tombol yaitu insert, update dan delete. Tombol insert digunakan untuk menyimpan data yang sudah ditambahkan oleh admin. Tombol update digunakan untuk memperbarui data yang akan diubah. Tombol delete digunakan untuk menghapus data. Proses tersebut dapat dijelaskan pada Gambar 8 .

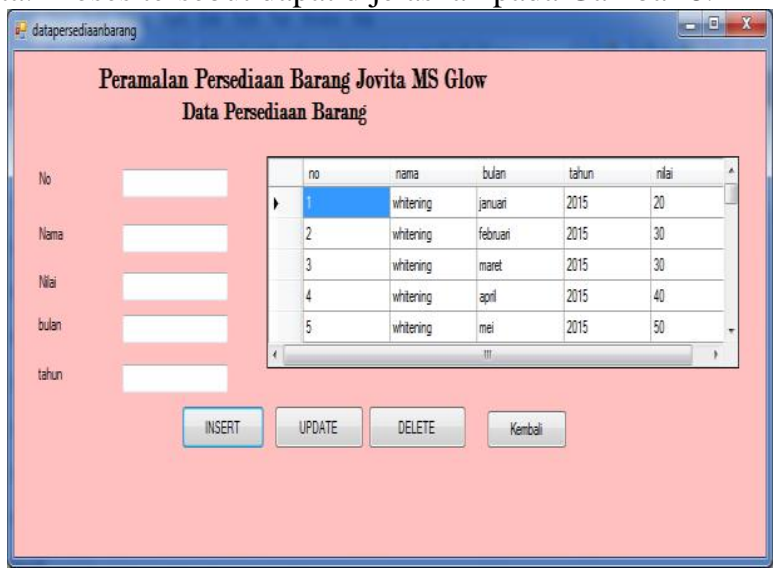

Gambar 8 Form Data Persediaan Barang 
Perhitungan persediaan barang dihitung menggunakan metode weight moving average. Proses tersebut dapat dijelaskan pada Gambar 9.

Perhitungan persediaan barang dihitung menggunakan metode double exponential smoothing yang menampilkan hasil prediksi dan nilai error. Proses tersebut dapat dijelaskan pada Gambar 10.

Pada form hasil akurasi terdapat nilai perhitungan metode weight moving average dan metode double exponential smoothing. Kemudian dibandingkan nilai eror terkecil antara dua metode tersebut dan dimasukkan pada hasil perbandingan.
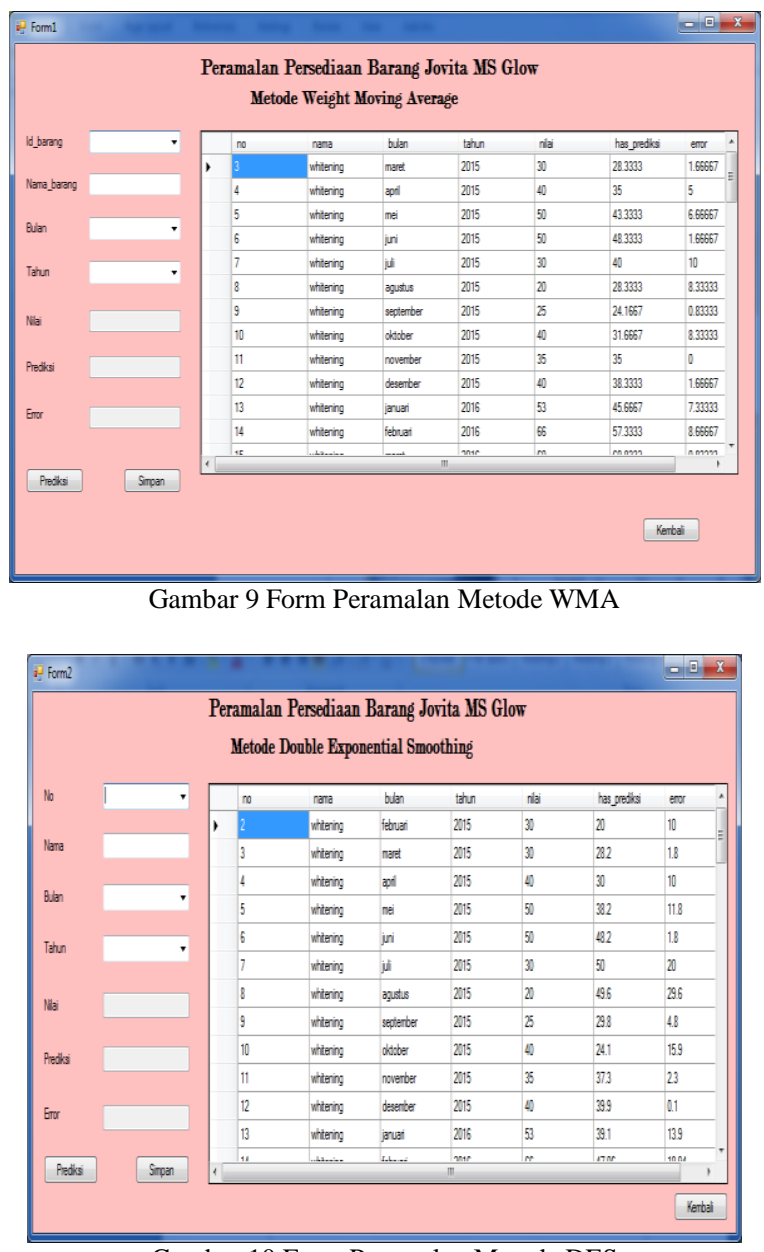

Gambar 10 Form Peramalan Metode DES

\section{KESIMPULAN}

Berdasarkan uraian dan hasil analisa yang telah dilakukan selama pengembangan Aplikasi Analisis Perbandingan Peramalan Persediaan Barang Menggunakan Metode Weight Moving Average dan Double exponential Smoothing Pada Jovita MS Glow Lamongan, kesimpulan yang dapat diambil adalah: Untuk studi kasus, persediaan barang pada Jovita MS Glow Lamongan dapat diterapkan metode Weight Moving Average sedangkan untuk metode Double Exponential Smoothing mempunyai tingkat nilai error yang lebih besar. Metode Weight Moving Average dalam sistem peramalan persediaan barang menghasilkan nilai error terkecil dibandingkan metode Double Exponential Smoothing.

\section{UCAPAN TERIMA KASIH / ACKNOLEDGMENT}

Terima kasih banyak kepada semua dosen Teknik Informatika yang telah memberikan pengetahuan dan ilmu kepada kami, terutama kepada Dosen pembimbing.

\section{DAFTAR PUSTAKA}

[1]Agus, Ristono. 2009. Manajemen persediaan edisi 1. Yogyakarta : Graha Ilmu.

[2]Lieberty, Annastasya. Et al. 2015. Sistem Informasi Peramalan Penjualan Barang Dengan Metode Double Exponential Smoothing (Studi Kasus : PD. Padalarang Jaya). Bandung : Jurnal Teknik Informatika dan Sistem Informasi Volume 1 Nomor 1.

[3] Baktiar, Cindy, dkk, 2014 Pembuatan Sistem Peramalan Penjualan Dengan Metode Weighted Moving Average dan Double Exponential Smoothing Pada UD Y.Universitas Kristen Petra.

[4] Render, Heizer. 2005. Penerapan Metode Single Moving Average dan Exponential Smoothing Dalam Peramalan Permintaan Produk Meubel Jenis Coffee Table Pada Java Furniture Klaten.

[5]Sahli, Muchamad. 2013. Penerapan Metode Exponential Smoothing Dalam Sistem Informasi Pengendalian Persediaan Bahan Baku (Studi Kasus Toko Tirta harum). Kudus : Jurnal SIMETRIS, Vol 3 No 1.

Azza Wirdhatul Zannah, alumni Teknik Informatika Universitas Islam Lamonga.

Nur Nafi'iyah lahir di Lamongan, 26 Januari 1987. Sekarang sebagai tenaga pengajar di Teknik Informatika Universitas Islam Lamongan. Alumni dari pascasarjana Teknologi Informasi Sekolah Tinggi Teknik Surabaya. Bidang penelitian kecerdasan buatan, pengolahan citra, data mining. 